\title{
A Ku-band CMOS Low-Noise Amplifier
}

\author{
Kuo-Liang Deng, Ming-Da Tsai, Chin-Shen Lin, Kun-You Lin, Huei Wang, \\ S. H. Wang*, W. Y. Lien* and John G. J. Chern*
}
Department of Electrical Engineering and Graduate Institute of Communication Engineering, National Taiwan University, Taipei, Taiwan, R.O.C. *Taiwan Semiconductor Manufacturing Co., Hsinchu, Taiwan, 300, R.O.C. Email: hueiwang@ew.ee.ntu.edu.tw

\begin{abstract}
A Ku-band monolithic low-noise amplifier is presented in this paper. This LNA fabricated in commercial 0.18- $\mu \mathrm{m}$ CMOS technology is a two-stage common-source design instead of cascode configuration for lower noise performance. This CMOS LNA demonstrates a gain of better than $10 \mathrm{~dB}$ and a NF of better than $3.2 \mathrm{~dB}$ from 14 to $15 \mathrm{GHz}$. The measured output $P_{1 \mathrm{~dB}}$ is about $5.2 \mathrm{dBm}$ and input IP3 is $1.6 \mathrm{dBm}$. The chip size including all testing pads is $0.88 \times 0.77$ $\mathbf{m m}^{2}$.
\end{abstract}

Index Terms-Ku band, CMOS, RFIC, microwave, lownoise amplifiers.

\section{INTRODUCTION}

Low-noise amplifiers (LNAs) are very important components of the RF front-end for transceiver application. As the wireless communication become more popular, operating frequency is moving toward higher frequency range for high data rate communication system. Most of the previously reported MMIC LNAs operated above $10 \mathrm{GHz}$ such as $\mathrm{Ku}$-band $(12-18 \mathrm{GHz})$ are implemented by using GaAs MESFET (or HEMT) process due to the high-gain, low-noise characteristics and low substrate loss [1]-[4]. However the high cost problem of the GaAs process is an important issue. Owing to the improvement of the CMOS technology in recent years, CMOS technology is another choice for the RF circuits above $10 \mathrm{GHz}$. Recently, a 24$\mathrm{GHz}$ and a 13-GHz CMOS LNAs were reported [5], [6]. For $\mathrm{Ku}$-band applications, a $12-\mathrm{GHz}$ silicon bipolar receiver was demonstrated for digital satellite applications [14].

A Ku-band LNA using standard commercial $0.18-\mu \mathrm{m}$ CMOS technology is demonstrated in this paper. This CMOS LNA demonstrates a measured gain of better than 10 $\mathrm{dB}$ and 3.2-dB NF at $14 \mathrm{GHz}$. Table I summarizes the previously reported CMOS LNAs operated above $7 \mathrm{GHz}$. Our chip demonstrates good NF and reasonable small-signal gain at $\mathrm{Ku}$ band.

\section{MMIC PROCESS}

This Ku-band LNA is implemented by commercial standard $0.18-\mu \mathrm{m}$ MS/RF CMOS technology which provides one poly layer for the gate of the MOS and six metal layers for inter-connection [9], [10]. The substrate conductivity is approximately $10 \mathrm{~S} / \mathrm{m}$. With optimized CMOS technology and deep n-well, this technology provides $f_{\mathrm{T}}$ and $f_{\mathrm{MAX}}$ of better than $60 \mathrm{GHz}$ and $55 \mathrm{GHz}$, respectively. High-Q inductors can be formed using the top $\mathrm{AlCu}$ metallization layer of $2-\mu \mathrm{m}$ thickness without additional masks. A MIM capacitor of $1 \mathrm{fF} / \mu^{2}$ has been developed using oxide intermetal dielectric.

\section{CIRCUIT DESIGN}

The typical CMOS LNA topology is cascode with the source inductance degeneration with the shortcoming of the relative high supply voltage. Since the drain of the commonsource stage is terminated with the source of the commongate device, the gain of the common-source stage is not high enough and the total noise performance will be degraded by the noise of the common-gate stage.

To achieve low supply voltage and avoid noise performance degradation, a common-source topology is adopted as in Fig. 1. The input matching condition and noise performance of an inductive degeneration topology with ideal inductors was fully analyzed in [13], and the parasitic resistance was also considered. The input impedance is

$$
Z_{i n}=s\left(L_{g}+L_{s}\right)+\frac{1}{s C_{g s}}+R_{g}+R_{L g 1}+R_{L s 1}+\frac{g_{m 1}}{C_{g s 1}} L_{s 1}
$$

where $C_{\mathrm{gs}}$ is the gate-source capacitance and $g_{m 1}$ is the transconductance of transistor M1. $R_{\mathrm{g}}$ is the effective gate resistance. $R_{L g 1}$ and $R_{L s 1}$ are the parasitic resistance of the inductors $L_{g 1}$ and $L_{s 1}$. The matching condition occurs when

$$
\begin{gathered}
\omega^{2} C_{g s}\left(L_{g}+L_{s}\right) \simeq 1 \\
R_{s}=R_{g}+R_{L g 1}+R_{L s 1}+\frac{g_{m 1}}{C_{g s}} L_{s}
\end{gathered}
$$

A two-stage topology is used to simultaneously optimize the gain and noise performances as in Fig. 1. The first stage is designed for noise performance and the second stage is designed for power gain. The transistor size of the first stage is $160 \mu \mathrm{m} / 0.18 \mu \mathrm{m}$, and the second stage is the same. 


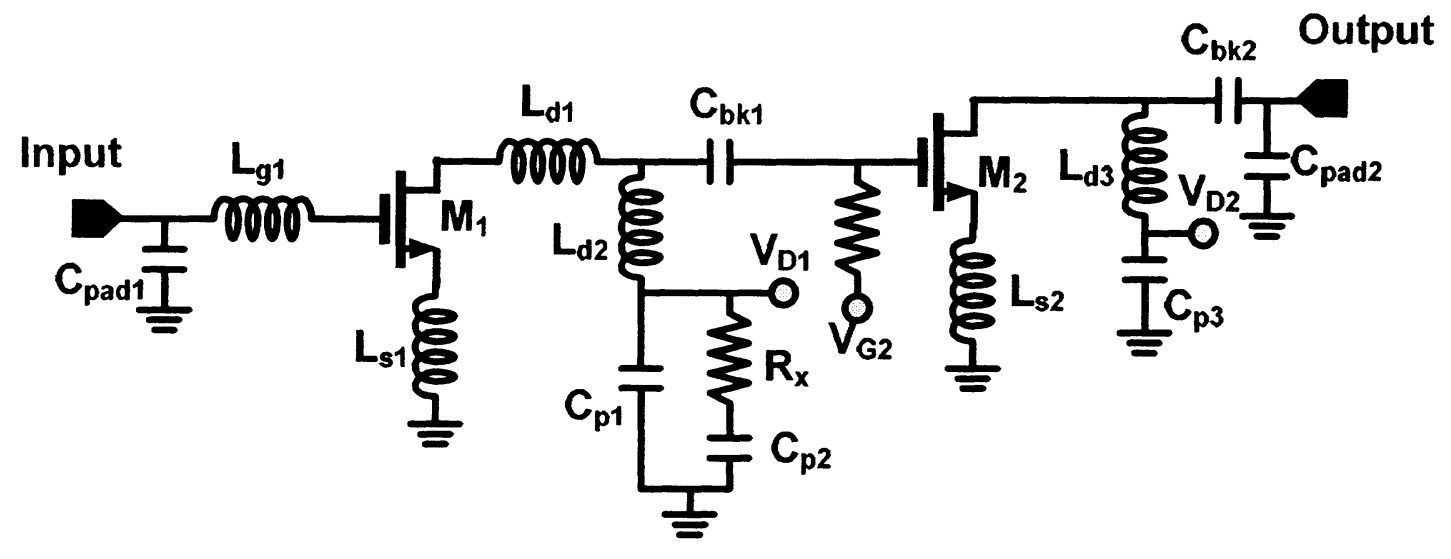

Fig. 1. Schematic of the Ku-band CMOS LNA.

The inter-stage is complex conjugate matched achieved by the inter-stage inductor $L_{d 1}$ and the drain inductor $L_{d 2}$. The inductance of $L_{d 1}$ and $L_{d 2}$ is 150 and $167 \mathrm{pH}$, respectively. The bias current of the input stage is fed through the bypass network, consists $C_{p 1}, C_{p 2}$ and $R_{x}$. The $C_{p 1}$ is design for inband bypass and $C_{p 2}$ for low-frequency band bypass. The $R_{x}$ is placed to depress the low-frequency gain and prevent resonance of bypass capacitor and effective inductance of the bias line (bonding wire or dc probe). The output impedance matching network is shunt-inductor $L_{\alpha 3}$. Since the operation frequency is $\mathrm{Ku}$ band, the parasitic capacitance of $\mathrm{I} / \mathrm{O}$ pads must also be considered. The RF pads are implemented by top metal with bottom ground-shielding metal. The complete schematic of the Ku-band LNA is in Fig. 1. All inductors are realized as planar inductors. For the drain bias networks, resistor and capacitor networks are designed for providing the RF short circuit and low frequency stability concern.

The circuit simulation was performed in the software, Agilent ADS (Advanced Design System) [11]. The models of the resistors and MIM capacitors are provided by the foundry, and the S-parameters of the inductors were simulated by the full-wave EM simulator, Sonnet [12]. Fig. 2 presents the chip photo of the Ku-band CMOS LNA, and the chip size is $0.88 \times 0.77 \mathrm{~mm}^{2}$.

\section{MEASUREMENT RESUlTS}

The LNA is measured via on-wafer probing. The measured NF and small-signal gain are shown in Fig. 3. The $\mathrm{NF}$ is better than $3.2 \mathrm{~dB}$ from 14 to $16 \mathrm{GHz}$ while the smallsignal gain is higher than $10 \mathrm{~dB}$ between $12.5 \mathrm{GHz}$ and 15 $\mathrm{GHz}$. The best measured NF and gain are $3.1 \mathrm{~dB}$ at $15 \mathrm{GHz}$ and $11 \mathrm{~dB}$ at $13.5 \mathrm{GHz}$, respectively. The measured input and output return losses are shown in Fig. 4. The input return loss is better than $10 \mathrm{~dB}$ from $13.5 \mathrm{GHz}$ to $18 \mathrm{GHz}$, and the output return loss is better than $10 \mathrm{~dB}$ from $11 \mathrm{GHz}$ to $18 \mathrm{GHz}$. The power performance of this amplifier is also measured at $14 \mathrm{GHz}$, and the measured results are shown in Fig. 5. The output and input $P_{1 \mathrm{~dB}}$ is about $5.2 \mathrm{dBm}$ and -5
$\mathrm{dBm}$, respectively. The measured input IP3 is $1.6 \mathrm{dBm}$, as shown in Fig. 6. The dc consumption is $1.3 \mathrm{~V} / 11 \mathrm{~mA}$ for each stage.

\section{CONCLUSION}

A CMOS LNA for Ku-band applications has been designed, fabricated and measured. This CMOS LNA demonstrates a gain of better than $10 \mathrm{~dB}$ and a NF of better than $3.2 \mathrm{~dB}$ from 14 to $15 \mathrm{GHz}$. The measured output $P_{1 \mathrm{~dB}}$ is about $5.2 \mathrm{dBm}$ and input IP3 is $1.6 \mathrm{dBm}$. The chip size including all testing pads is $0.88 \times 0.77 \mathrm{~mm}^{2}$.

\section{ACKNOWLEDGMENT}

This work is supported in part by NTU-TSMC JointDevelopment Project, and National Science Council (NSC 93-2752-E-002-002-PAE, NSC 93-2219-E-002-024 and NSC 93-2213-E-002-033). The chip is fabricated by Taiwan Semiconductor Manufacturing Company.

\section{REFERENCES}

[1] T. Yoshimasu, K. Sakuno, N. Matsumoto, E. Suematsu, T. Tsukao, and T. Tomita, "A low-current $\mathrm{Ku}$-band $\mathrm{GaAs}$ monolithic image rejection down-converter," IEEE J. Solid State Circuits, vol. 27, no. 10, pp. 1448-1451, Oct. 1992.

[2] K. Sakuno, T. Yoshimasu, N. Matsumoto, T. Tsukao, T. Nakagawa, E. Suematsu, and T. Tomita, "A miniature low current GaAs MMIC downconverter for $\mathrm{Ku}$-band broadcast satellite applications," in 1992 IEEE Microwave \& Millimeter-wave Monolithic Circuits Symposium Digest, pp.101-104, June 1992.

[3] K. Yamanaka, K. Yamauchi, K. Mori, Y. Ikeda, H. Ikematsu, N. Tanahashi, and T. Takagi, "Ku-band low noise MMIC amplifier with bias circuit for compensation of temperature dependence and process variation," in 2002 IEEE International Microwave Symposium Digest, vol. 2, pp. 1427-1430, June 2002.

[4] [4] P. K. Ikalainen, L. C. Witkowski, and K. R. Varian, "Low-noise, low DC power linear amplifiers," in 1993 IEEE Microwave \& Millimeter-wave Monolithic Circuits Symposium Digest, pp.159162, June 1993.

[5] K. W. Yu, Y. L. Lu, D. Huang, D. C. Chang, V. Liang, and M. F. Chang, "24 GHz low-noise amplifier in $0.18 \mu \mathrm{m}$ CMOS technology," IEE Electronic Letters, vol. 39, Issue 22, pp. 1559- 
1560,30 Oct. 2003

[6] J. Gil, K. Han, and H. Shin, " $13 \mathrm{GHz} 4.67 \mathrm{~dB}$ NF CMOS low-noise amplifier," IEE Electronic Letters, vol. 39, Issue 14, pp. 1056-1058, 10 July 2003.

[7] R. Fujimoto, K. Kojima, and S. Otaka, "A 7-GHz 1.8-dB NF CMOS low-noise amplifier," IEEE J. Solid State Circuits, vol. 37 , no. 7 , pp. $852-856$, July 2002.

[8] T. K. K. Tsang, and M. N. El-Gamal, "Gain controllable very low voltage $(<1 \mathrm{~V}) 8-9 \mathrm{GHz}$ integrated CMOS LNAs," in 2002 IEEE Radio Frequency Integrated Circuits Symposium Digest, pp. 205207, June 2003

[9] H. M. Hsu, J. Y. Chang, J. G. Su, C. C. Tsai, S. C. Wong, C. W. Chen, K. R. Peng, S. P. Ma, C. H. Chen, T. H. Yeh, C. H. Lin, Y. C Sun, and C. Y. Chang, "A $0.18-\mu \mathrm{m}$ foundry RF CMOS technology with $70-\mathrm{GHz} \mathrm{ft}$ for single chip system solutions, "in JEEE MTT-S Int. Microwave Symp. Dig., vol. 3, pp. 1869-1872, 2001.

[10] C. H. Diaz, et al., "A 0.18- $\mu \mathrm{m}$ CMOS Logic Technology with Dual Gate Oxide and Low-k Interconnect for High-Performance and Low-Power Applications," IEEE VLSI Tech. Symp., pp. 11-12, 1999.

[11] Advanced Design System User's Guide, Agilent Technologies Inc

[12] Sonnet user's manual, Sonnet Software, Inc.

[13] D. K. Shaffer, and T. Lee, "A 1.5-V, 1.5-GHz CMOS low noise amplifier, "IEEE J. Solid-State Circuits, vol. 32, pp. 745-759, Jun 1997

[14] G. Girlando, T. Copani, S. A. Smerzi, A. Castorina, and Palmisano, "A $12 \mathrm{GHz}$ silicon bipolar receiver for digital satellite applications," ISSCC Dig. Tech. Papers, pp.276-277, Feb. 2004.

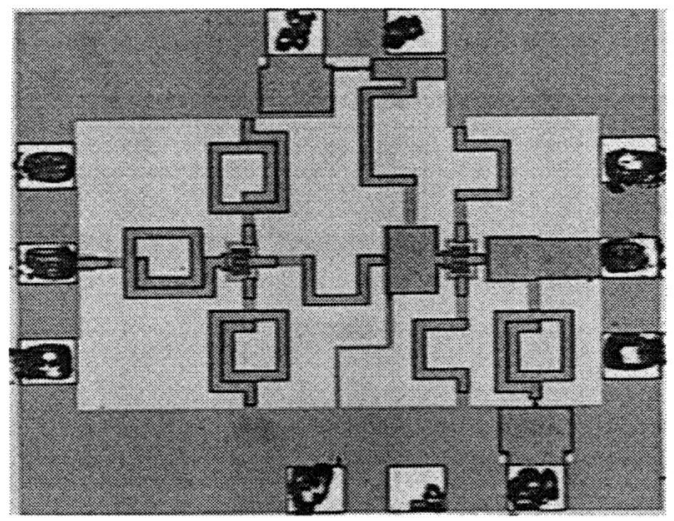

Fig. 2. Chip photo of the Ku-band CMOS LNA, and the chip size is $0.88 \mathrm{x}$ $0.77 \mathrm{~mm}^{2}$.

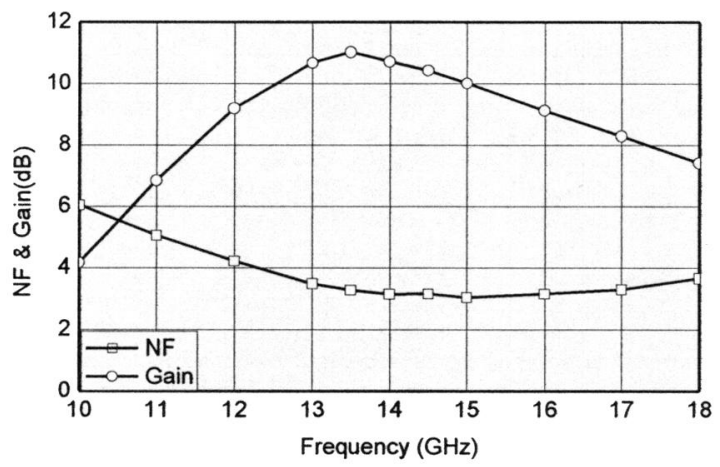

Fig. 3. Measured NF and small-signal gain of the Ku-band CMOS LNA.

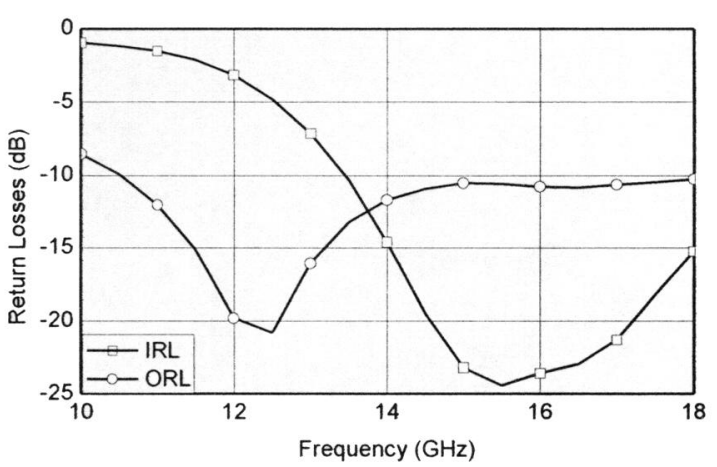

Fig. 4. Measured input and output return losses of the Ku-band CMOS LNA.

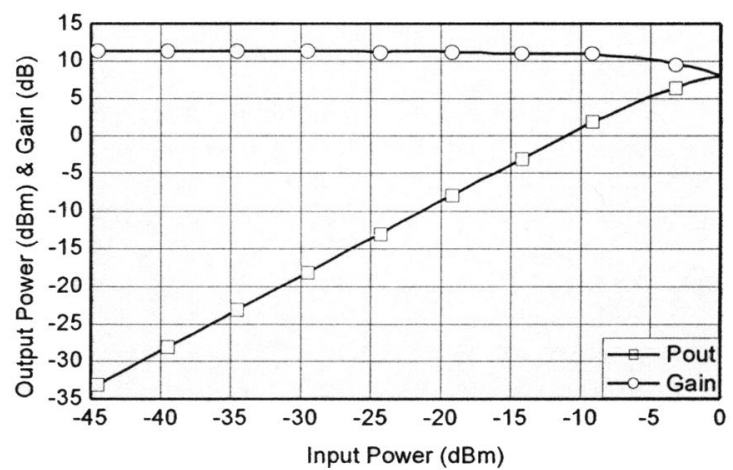

Fig. 5. Measured output power versus input power of the LNA at $14 \mathrm{GHz}$

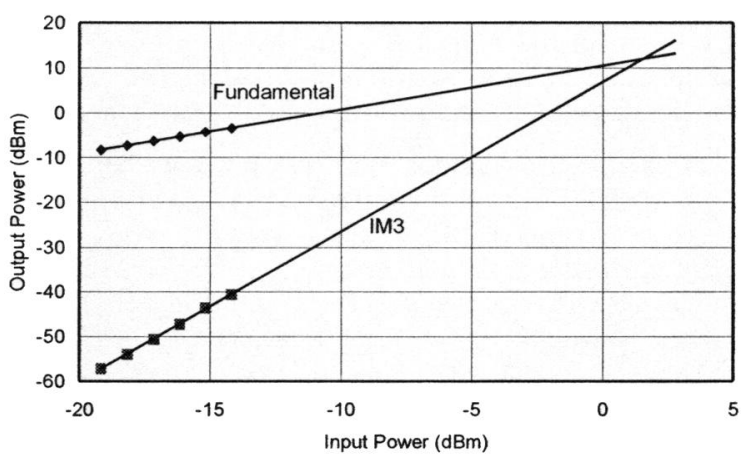

Fig. 6. Measured IP3 
TABLE I. THE PREVIOUSLY REPORTED CMOS LNAS OPERATED ABOVE $7 \mathrm{GHZ}$.

\begin{tabular}{|c|c|c|c|c|c|c|c|c|}
\hline References & Process & Architecture & $\begin{array}{c}\text { Frequency } \\
(\mathrm{GHz})\end{array}$ & Gain (dB) & $N F(d B)$ & $\begin{array}{c}P_{1 \mathrm{~dB}} \\
(\mathrm{dBm})\end{array}$ & $\begin{array}{c}\text { DC } \\
\text { Consumption }\end{array}$ & $\begin{array}{l}\text { Chip Size } \\
\left(\mathrm{mm}^{2}\right)\end{array}$ \\
\hline $\begin{array}{c}\text { K. W. Yu et al., } \\
{[5]}\end{array}$ & $\begin{array}{l}0.18-\mu \mathrm{m} \\
\mathrm{CMOS}\end{array}$ & $\begin{array}{c}\text { CS } \\
3 \text { stages }\end{array}$ & 23.5 & 12.86 & 5.6 & - & $1.8 \mathrm{~V} / 30 \mathrm{~mA}$ & $1.05 \times 0.7$ \\
\hline J. Gil et al., [6] & $\begin{array}{l}0.18-\mu \mathrm{m} \\
\text { CMOS }\end{array}$ & $\begin{array}{l}\text { Cascode } \\
1 \text { stage }\end{array}$ & 13 & 4.9 & 4.67 & IIP3: 8.5 & $1.8 \mathrm{~V} / 5.4 \mathrm{~mA}$ & $0.31 \times 0.33$ \\
\hline $\begin{array}{c}\text { R. Fujimoto et } \\
\text { al., [7] }\end{array}$ & $\begin{array}{l}0.25-\mu \mathrm{m} \\
\mathrm{CMOS}\end{array}$ & $\begin{array}{c}\text { Cascode } \\
1 \text { stage }\end{array}$ & 7 & 6.2 & 3.3 & 1.6 & $2 \mathrm{~V} / 6.9 \mathrm{~mA}$ & $0.86 \times 0.61$ \\
\hline $\begin{array}{l}\text { T. T. K. Tsang } \\
\text { et al., }[8]^{*}\end{array}$ & $\begin{array}{l}0.18-\mu \mathrm{m} \\
\text { CMOS }\end{array}$ & $\begin{array}{c}\text { Folded cascode } \\
1 \text { stage }\end{array}$ & 8 & 13.5 & 3.2 & -13.2 & $1 \mathrm{~V} / 22.4 \mathrm{~mA}$ & - \\
\hline $\begin{array}{l}\text { T. T. K. Tsang } \\
\text { et al., }[8]^{*}\end{array}$ & $\begin{array}{l}0.18-\mu \mathrm{m} \\
\text { CMOS }\end{array}$ & $\begin{array}{c}\text { Folded cascode } \\
1 \text { stage }\end{array}$ & 9 & 12.2 & 3.7 & -8.7 & $1 \mathrm{~V} / 19.8 \mathrm{~mA}$ & $1 \times 0.9$ \\
\hline This Work & $\begin{array}{l}0.18-\mu \mathrm{m} \\
\mathrm{CMOS}\end{array}$ & $\begin{array}{c}\text { CS } \\
2 \text { stages }\end{array}$ & 14 & 10.71 & 3.16 & 5.16 & $1.3 \mathrm{~V} / 22 \mathrm{~mA}$ & $0.88 \times 0.77$ \\
\hline
\end{tabular}

$*$ : variable gain amplifier, gain control range $>10 \mathrm{~dB}$ 